\title{
AGE DYNAMICS OF PANCREAS SECRETORY FUNCTION AND INTESTINAL MICROBIOTA IN MEAT BROILER CHICKS AND THEIR PARENTAL LINES
}

\section{I.A. EGOROV'1, V.G. VERTIPRAKHOV ${ }^{1}$, A.A. GROZINA¹, G.Yu. LAPTEV ${ }^{2}$, I.N. NIKONOV ${ }^{2}$, N.I. NOVIKOVA2 ${ }^{2}$ L.A. ILINA ${ }^{2}$, E.A. YILDIRIM ${ }^{2}$, V.A. FILIPPOVA ${ }^{2}$, A.V. DUBROVIN ${ }^{2}$, V.A. MANUKYAN1, T.N. LENKOVA1}

\begin{abstract}
${ }^{1}$ Federal Scientific Center All-Russian Research and Technological Poultry Institute RAS, Federal Agency of Scientific Organizations, 10, ul. Ptitsegradskaya, Sergiev Posad, Moscow Province, 141315 Russia, e-mail olga@vnitip.ru; $2 J S C$ «Biotrof + », pom. 7-n, 8 liter A, ul. Malinovskaya, St. Petersburg-Pushkin, 196602 Russia, e-mail nikonov@biotrof.ru (corresponding author);

ORCID:

Vertiprakhov V.G. orcid.org/0000-0002-3240-7636

Grozina A.A. orcid.org/0000-0002-3088-0454

The authors declare no conflict of interests

Acknowledgements:

Supported by grant from Russian Science Foundation, project 16-16-04089 "Embryonal and post embryonal physiological and microbiological study of digestion in meat hens for developing new feeding technologies able to provide maximum realization of poultry genetic potential"

Received January 21, 2017
\end{abstract}

\section{Abstract}

The distinctive feature of avian digestion is high activities of the digestive enzymes. The digestion of poorly hydrolysable feed ingredients is known to be partially performed by microbial communities of cecum and large intestine (B. Svihus et al., 2013). The aim of our study was the investigation of embryonic and postembryonic enzymatic and microbial digestive processes in the intestine of meat-type chicken of parental lines B5 (Cornish), B9 (Plymouth Rock) and final hybrids (B59 Smena 8 cross) of Smena Selective-Genetic Centre (Russia) on ontogenesis (7- and 14-day old embryos, and 1-, 7-, 14-, 21-, 28-, and 35-day old chicks; 20 incubated eggs and 20 chicks per age in total; the experiment was carried out in the vivarium of All-Russian Research and Technological Poultry Institute). Activity of pancreatic enzymes (amylase and lipase) was detected in homogenates of the whole embryos (day 7 of incubation) and the embryonic intestinal and pancreatic tissues (day 14 of incubation). In day-old chicks high levels of pancreatic enzymes in the pancreas were found with no significant differences between parental lines and final hybrids in early postnatal period. According to the exocrine function of the pancreas, postnatal ontogenesis can be divided into two periods. In 1-14 day-old chicks the pancreas and its digestive function intensively develop, and the next period (from day 15 to day 35 ) is necessary to reach physiological maturity of the organ which becomes capable of enzyme production and secretion adequate to the diet. The activity of blood pancreatic amylase and proteases tended to decrease with age, and lowered significantly on day 35 . The lipase activity followed the inverse trend and sinuously increased to day $35(\mathrm{P} \leq 0.05)$. The percentage of cellulolytic bacteria in intestinal microbiota reached its peak on day 14 without significant differences between the hybrids $(50.79 \pm 1.84 \%)$ and the parental lines $(50.84 \pm 2.32$ and $53.23 \pm 2.47 \%)$. This percentage subsequently decreased by $60.0 \%$ in the hybrids from day $14(50.80 \pm 1.84 \%)$ to day 35 $(20.30 \pm 0.85 \%)$, while in the parental lines there were sinuous variations throughout this period with $41.00 \pm 1.87 \%$ and $44.80 \pm 2.27 \%$ on day 35 in Plymouth Rock and Cornish, respectively. These data suggests a negative correlation between activity of pancreatic proteases and intestine cellulolytic bacteria. The highest $r$ values were noted for Clostridium $(-0.64,-0.83$ and -0.64 for Cornish, Plymouth Rock and the hybrid chicks, respectively). The proportion of Lactobacillales that participate in feed fermentation positively correlated with the activity of amylase, lipase and protease in the hybrids $(r=0.71, r=0.56$, and $r=0.83)$ and in the Plymouth Rock line $(r=0.60, r=0.46$, and $r=0.45$ ). A positive correlation was mostly found between the activity of pancreatic enzymes and the development of opportunistic and pathogenic microflora, i.e. Enterobacteriaceae (for amylase, lipase and proteases $r=0.65, r=0.59, r=0.68$ in the hybrids, and $r=0.34, r=0.68, r=0.64$ in the Cornishes, respectively), Staphylococcus (for protease $r=0.46$ in the Cornishes, for amylase and proteases $r=0.70$ and $r=0.91$ in the Plymouth Rock line), Campylobacterium (for proteases $r=0.86$ in the hybrids) and Fusobacterium (for amylase and proteases $r=0.41$ and $r=0.90$ in hybrids, for lipase and protease $r=0.63$ and $r=0.83$ in the Cornishes, for amylase and proteas- 
es $r=0.99$ and $r=0.92$ in the Plymouth Rock line). Thus, the intensive development of individuals is due to the activity of digestive enzymes which is interrelated with the quantitative and qualitative composition of the intestinal microbiota. Regarding the analyzed indicators, embryogenesis and early post-embryonic periods should be considered crucial for chicken development.

Keywords: meat-type chicken, broiler chicks, Plymouth Rock, Cornish, exocrine pancreatic function, gut microbiota, pancreatic enzymes in blood serum

Effective feed cleavage for further assimilation of nutrients is one of the most important factors in livestock growing. Fundamental research of the digestive system is based on revealing the molecular and cellular mechanisms of its functioning, while being interrelated with other body systems. Deterioration of digestion and assimilation of nutrients may be a result of violation of physiological and biochemical processes caused by the problems with intestinal health that are related to feed quality and the state of the microbiota [1-3]. This has serious implications for commercial poultry farming, in particular, leads to deterioration in feed conversion, increases risk of diseases and reduces profitability [4, 5]. Moreover, recent changes in legislation in the EU countries on using antibiotics and feeding, as well as the genetic improvement of the poultry itself, require a deeper study of intestine function and health.

The results of studying preparations alternative to antibiotics show that the body weight gain in broilers can significantly increase via the effect on the composition of the intestinal microflora [6-10]. It is known that digestion in poultry occurs due to its own digestive enzyme, secreted by the digestive glands, and a certain role in the digestion of hardly hydrolysable feed components is played by the microflora in cecum and large intestine [11-13]. It is unlikely that digestive enzymes do not affect the composition of microflora in the poultry intestine. However, the available scholarly publications lack such data, especially the data considering the age dynamics and comparing the parent lines and hybrids on the parameters in question.

In this study, having examined the activity of pancreatic enzymes in ontogenesis in meat chicks and their hybrids, and having compared it with the quantitative composition of the intestinal microbiota, we established a correlation between these indices.

The aim of our work was to study embryonic and postembryonic enzymatic and microbial processes in the intestines of parental lines and hybrids of meat chicken.

Techniques. The experiments were carried out on the Cornish (line B5) and Plymouth Rock (line B9) chicken breeds and their hybrids (B59, the cross Smena 8) of the Smena Selective-Genetic Centre (Russia).

During eggs incubation (units Stimul-1000, Stimul-Ink, Russia), embryos aged 7 days and digestive system of the embryos aged 14 days were examined in the groups (hybrids, maternal and paternal lines). For each variant, 10 eggs from each group were used. Experiments were conducted in two replicates. The embryo samples were homogenized with a cooled Ringer's solution at a ratio of 1:10 and centrifuged at $5000 \mathrm{rpm}$ for 5 minutes. Enzymatic activity was determined by Smith-RoyUgolev method using an automatic biochemical analyzer Hemwell T2900 (Awareness Technology, Inc., USA) with Pancrease-amylase liquicolor and Lipase liquicolor kits (HUMAN GmbH, Germany) according to the manufacturers' instructions.

The development of pancreatic exocrine function during ontogenesis was studied in the experimental farm conditions (All-Russian Research and Technological Poultry Institute, the feeding and housing schedules met the zootechnic requirements). In each age period $(1,7,14,21,28$ and 35 days of life), 10 chickens were used. Experiments were conducted in two replicates. Blood for analysis was taken after slaughter by decapitation. Sodium citrate was added to the sam- 
ples, and they were centrifuged at $5000 \mathrm{rpm}$ for 5 minutes. The abdomen wall was dissected and the pancreas was removed, weighed and ground with cooled Ringer's solution. The homogenate was centrifuged at $1200 \mathrm{rpm}$ for 3 minutes. The appropriate supernatant dilution was used for biochemical analysis. The intestine was tied, taken out and exposed to deep freezing for subsequent microbiological assay. The intestinal content samples for molecular genetic analysis were collected simultaneously with those collected for biochemical studies, as established by corresponding requirements [14]. In pancreatic tissue, the amylase activity was determined by starch cleavage (Smith-Roy-Ugolev method); protease activity was determined colorimetrically by a decrease in casein concentration [15]; lipase was measured with the use of a semi-automatic biochemical analyzer BS3000P (SINNOWA, PRC) with an appropriate kit of diagnostic reagents (DIAKONVET, Russia). The blood amylase and lipase activities were examined with a Hemwell 2900 (T) biochemical analyzer (Awareness Technology, Inc., USA) using required kits (HUMAN GmbH, Germany). Protease activity was studied on a biochemical analyzer BS3000P (SINNOWA, PRC) with N-benzoyl-DL-argininep-nitranilide (BAPNA) as a substrate [16].

Total DNA was extracted using Genomic DNA Purification Kit (Fermentas, Inc., Lithuania) according to manufacturer's recommendations. DNA amplification was performed on a Verity device (Life Technologies, Inc., USA) using eubacterial primers 63F (3'-CAGGC-CTAACACATGCAAGTC-5') labeled at the 5'-end (D4 WellRed fluorophore) and 1492R (3'-TACGGHTACCTTGTTACGACTT-5'), which allow amplifying fragment of the 16S rRNA gene at positions from 63 to 1492 (numeration is indicated for the Escherichia coli 16S rRNA gene). The amplification protocol was as follows: $3 \mathrm{~min}$ at $95{ }^{\circ} \mathrm{C}$ (1 cycle); $30 \mathrm{~s}$ at $95{ }^{\circ} \mathrm{C}, 40 \mathrm{~s}$ at $55^{\circ} \mathrm{C}, 60 \mathrm{~s}$ at $72{ }^{\circ} \mathrm{C}(35$ cycles $) ; 5 \mathrm{~min}$ at $72{ }^{\circ} \mathrm{C}$. The fluorescently labeled amplicons of the 16S rRNA gene were purified with $3 \mathrm{M}$ guanidine isothiocyanate. The final concentration of total DNA was determined with a Qubit fluorimeter (Invitrogen, Inc., USA) using the Qubit dsDNA BR Assay Kit (Invitrogen, Inc., USA) according to the manufacturer's recommendations. Restriction of 30-50 ng DNA with endonuclease HaeIII, HhaI and MspI (Fermentas, Lithuania) was carried out for 2 hours at $37^{\circ} \mathrm{C}$. Restricts were precipitated with ethanol, then $0.2 \mu$ of Size Standart-600 molecular weight marker (Beckman Coulter, USA) and $10 \mu \mathrm{l}$ of Sample Loading Solution formamide (Beckman Coulter, USA) were added. The samples were analyzed using a CEQ 8000 device (error $5 \%$ max, Beckman Coulter, USA).

The height of peaks and their areas were calculated in the Fragment Analysis software (Beckman Coulter, USA). Based on the calculation, the subtypes (phylotypes) with a one nucleotide error accepted for this study were distinguished and their relative amount in the microbial community was evaluated. Phylogenetic status of bacteria was determined using Fragment Sorter software (http://www.oardc.ohiostate.edu/trflpfragsort/in-dex.php).

Real-time PCR to estimate the total bacterial abundance was performed using a DT Lite-4 amplifier (OOO NPO DNA Technology, Russia) with the Reagents for RT-PCR in the presence of intercalating EVA Green stain Kit (ZAO Syntol, Russia ) and Eub338/Eub518 (5'-ACTCCTACGGGAGGCAGCAG-3' and $5^{\prime}$-ATTACCGCGG-CTGCTGG-3') primers, in the following regime: $3 \mathrm{~min}$ at $95{ }^{\circ} \mathrm{C} ; 13 \mathrm{~s}$ at $95{ }^{\circ} \mathrm{C}, 13 \mathrm{~s}$ at $57{ }^{\circ} \mathrm{C}, 30 \mathrm{~s}$ at $72{ }^{\circ} \mathrm{C}$ (40 cycles).

The average $(X)$ and standard errors of the mean $( \pm \mathrm{SEM})$ were calculated for the enzyme activity indices. The reliability of the differences was determined by the Student's $t$-test, considering them significant when $\mathrm{p} \leq 0.05$. To explain the cause and effect between the factor and performance traits, the Pearson correla- 
tion coefficients were calculated, assuming them high at $r \geq 0.5$. Mathematical and statistical processing, as well as calculation of Pearson correlation coefficients, was performed in Past software (http://folk.uio.no/ohammer/past/).

Results. The hybrids showed the amylolytic activity in the week-old embryo homogenate 8-19 times higher than that of the maternal line and 1622 times higher than that of the paternal line. Lipolytic activity was $28.5 \%$ and $25.1 \%$ higher than that in the maternal and paternal lines, respectively. Proteolytic activity was not observed in 7-week old embryos. Given the development of the intestine and pancreas in embryos begins since day 3 to day 4, the presence of amylolytic and lipolytic activity in embryonic tissues was quite understandable. In eggs, there is a small amount of monosaccharides, and most proteins are present in the form of glycoproteids. Probably, as a result of the degradation of these proteins during embryogenesis, the released carbohydrates monomers are used for the glycosilation of newly synthesized polypeptides. On day 14 of incubation, the amylase activity in hybrids was 1.4-2.0 times higher compared to the parental lines. The lipase showed the opposite trend: the hybrids had almost twice lower activity than that of parental lines. At this stage, the embryos already have functioning digestion, and the results indicate a more intensive fat hydrolysis in the Plymouth Rocks and Cornishes intestines, if compared to their hybrids. Hence, this data indicates that the amylase activity in hybrid embryos, which afterwards have a high growth rate, is greater than that of their parents. This indicator may serve as a criterion for assessing the development of embryos and poultry performance in the future.

1. Age-related changes in enzyme activity of pancreatic tissue in hybrids and parental lines of poultry of different breeds $(X \pm \mathrm{SEM}$, experimental farm)

\begin{tabular}{|c|c|c|c|c|c|c|}
\hline \multirow{2}{*}{ Group } & \multicolumn{6}{|c|}{ Age, days } \\
\hline & 1 & 7 & 14 & 21 & 28 & 35 \\
\hline \multicolumn{7}{|c|}{ A m y la se, $\mathrm{mg} /(\mathrm{g} \cdot \mathrm{min})$} \\
\hline Hybrids & $14040 \pm 828.3$ & $12287 \pm 1017.3$ & $18440 \pm 443.8$ & $13800 \pm 2057.2$ & $15160 \pm 1254.7$ & $17343 \pm 617.5$ \\
\hline Plymouth Rock & $13080 \pm 1149.2$ & $8712 \pm 628.5^{*}$ & $14075 \pm 1205.0$ & $11500 \pm 538.1$ & $15480 \pm 1234.0$ & $16320 \pm 1120.0$ \\
\hline Cornish & $14200 \pm 1225.2$ & $10780 \pm 1248.2$ & $13300 \pm 1116.1$ & $9440 \pm 401.3$ & $10680 \pm 2670.7$ & $14840 \pm 1594.3$ \\
\hline \multicolumn{7}{|c|}{ Prote in a s e $\mathrm{s}, \mathrm{mg} /(\mathrm{g} \cdot \min )$} \\
\hline Hybrids & $323 \pm 30.7$ & $200 \pm 12.1$ & $317 \pm 48.9$ & $278 \pm 30.1^{*}$ & $325 \pm 46.9$ & $487 \pm 43.2$ \\
\hline Plymouth Rock & $314 \pm 21.1$ & $125 \pm 15.7$ & $246 \pm 32.2$ & $192 \pm 50.0$ & $206 \pm 22.6$ & $402 \pm 32.2$ \\
\hline Cornish & $261 \pm 36.1$ & $126 \pm 14.1$ & $175 \pm 26.6$ & $217 \pm 68.6$ & $226 \pm 24.7$ & $403 \pm 87.4$ \\
\hline \multicolumn{7}{|c|}{$\mathrm{L} \mathrm{i} \mathrm{p} \mathrm{a} \mathrm{s} \mathrm{e,} \mathrm{EU/l}$} \\
\hline Hybrids & $31288 \pm 4401.7$ & $90489 \pm 6648.5^{*}$ & $99882 \pm 4621.7^{*}$ & $107645 \pm 6196.0^{*}$ & 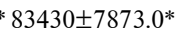 & $105753 \pm 4095.5^{*}$ \\
\hline Plymouth Rock & $38582 \pm 4391.7$ & $67074 \pm 6735.0^{*}$ & $81209 \pm 7965.0 *$ & $95390 \pm 8985.0 *$ & $88906 \pm 10569.3^{*}$ & $85940 \pm 7808.0 *$ \\
\hline Cornish & $39670 \pm 5551.0$ & $64255 \pm 7044.3^{*}$ & $92307 \pm 4371.3^{*}$ & $94250 \pm 8300.0 *$ & $70135 \pm 3634.0 *$ & $88039 \pm 11537.5^{*}$ \\
\hline
\end{tabular}

Analysis of pancreatic tissue homogenates in a day-old chicks revealed significant amylolytic, lipolytic and proteolytic activity, but there were no significant differences in these parameters in different groups (Table 1). In course of ontogenesis, the exocrine action of the pancreas develops unevenly [17]. During the first weeks of postembryonic development, chicks adapt to new living conditions, and formation of the digestive system occurs. Therefore, there are differences in the growth rates of chickens of different groups (hybrids, the Cornishes and the Plymouth Rocks) [18, 19].

When the chicks aged 14 days, the amylase activity in the pancreatic tissue of the hybrids was $31.3 \%$ higher $(\mathrm{P} \leq 0.05)$ compared to a day old chicks, but did not change significantly in the parental lines (see Table 1). Proteinase activity after a decrease at the age of 7 days (by $38.1 \%$ in hybrids, and by 60.2 and $57.1 \%$, respectively, in the chicks of the maternal and paternal lines, $\mathrm{P} \leq 0.05$ ) increased by day 14, reaching the values recorded in the first day of life. Lypolytic activity tended to increase, and in 14-day old chicks it significantly $(P \leq 0.05)$ ex- 
ceeded the indices in day-old chicks, being 3.2 times higher in the hybrids, 2.1 times higher in the maternal line, and 2.3 times higher in the paternal line. Comparative analysis shows that at the age of 14 days the amylolytic activity in the hybrids was significantly ahead of that in the parental lines (by $23.7 \%$ for the maternal line, and by $27.9 \%$ for the paternal line). Taking into account that amylase is involved in the hydrolysis of carbohydrates and determines the energy balance in the body, the intensity of metabolic processes in hybrids in this period is significantly higher than that of peers from the parental lines. The 2-week old chicks did not show significant differences between groups in lipase activity, whereas pancreatic proteases were much more active in hybrids than in parental lines (paternal score was lower by $44.8 \%, \mathrm{P} \leq 0.05$, and maternal score was lower by $22.4 \%$ ). The difference in the hydrolysis of feed protein was due to the unequal nutritional value of diets for hybrids and parental lines (in broiler chickens, the content of crude protein in feed was $22.0 \%$, and in parental lines it did not exceed $19.0 \%$ ). The difference in proteolytic activity in pancreatic tissue in chicks from different groups indicated the features determined by the genetic potential and the adaptation of pancreatic secretion to feed quality. Thus, by age of two weeks, the exocrine function of the pancreas in meat-type chickens clearly adapts to the quality of the feed taken. This fact indicates the onset of the gland physiological maturity, since according to functional criteria (including neurohumoral regulation), the organ corresponds to that of adult chickens.

The second period (days 15-35) was characterized by a decrease in proteinase activity in 21-day old age compared to the figures recorded at a day old age, by $14 \%$ in hybrids $(P \leq 0.05)$ and by $38.9 \%$ in chicks of the maternal line with a subsequent growth up to 35-day old age. The 35-day old hybrid chicks exceeded a day old ones by $23.5 \%$ ( $\mathrm{P} \leq 0.05)$ for amylase activity, by $50.8 \%$ f or proteinase activity, and by $238.0 \%$ for lipase activity. Between the groups at the age of 35 days, no significant differences in the activity of the enzymes were found, except the lipase. Its activity in the maternal line chicks was $18.7 \%$ lower $(\mathrm{P} \leq 0.05)$ than that in the hybrids.

The role of pancreas is not limited to digestion, but includes endocrine function, i.e. production of hormones (insulin, glucagon, and somatostatin). Pancreas is also involved in metabolic control due to the presence of pancreatic enzymes in blood [20, 21]. Therefore, we studied their activity in blood in growing hybrids and chicks of the original lines (Table 2).

2. Age-related changes in blood pancreatic enzyme activity in hybrids and parental lines of poultry of different breeds ( $X \pm \mathrm{SEM}$, experimental farm)

\begin{tabular}{|c|c|c|c|c|c|c|}
\hline \multirow{2}{*}{ Group } & \multicolumn{6}{|c|}{ Age, days } \\
\hline & 1 & 7 & 14 & 21 & 28 & 35 \\
\hline \multicolumn{7}{|c|}{$\mathrm{Am}$ y 1 a s e, EU/l } \\
\hline Hybrids & $671 \pm 50.5$ & $1001 \pm 21.4^{*}$ & $1296 \pm 358.3^{*}$ & $525 \pm 95.0$ & $516 \pm 86.7$ & $298 \pm 28.2^{*}$ \\
\hline Plymouth Rock & $929 \pm 92.9$ & $926 \pm 107.9$ & $832 \pm 136.3$ & $445 \pm 103.7^{*}$ & $642 \pm 82.3^{*}$ & $605 \pm 86.3^{*}$ \\
\hline Cornish & $827 \pm 132.9$ & $704 \pm 66.3$ & $583 \pm 56.6^{*}$ & $382 \pm 39.0^{*}$ & $564 \pm 124.0$ & $510 \pm 71.3^{*}$ \\
\hline \multicolumn{7}{|c|}{ Prote in as es, EU/l } \\
\hline Hybrids & $14 \pm 1.3$ & $15 \pm 1.5$ & $11 \pm 0.5$ & $10 \pm 3.6$ & $13 \pm 1.6$ & $8 \pm 1.6^{*}$ \\
\hline Plymouth Rock & $14 \pm 1.4$ & $13 \pm 0.9$ & $13 \pm 1.1$ & $6 \pm 0.7 *$ & $10 \pm 1.1$ & $9 \pm 0.7 *$ \\
\hline Cornish & $15 \pm 0.8$ & $12 \pm 0.7$ & $11 \pm 0.6$ & $7 \pm 0.1$ & $8 \pm 0.8$ & $13 \pm 1.4$ \\
\hline \multicolumn{7}{|c|}{$\mathrm{L}$ i p a s e, EU/1 } \\
\hline Hybrids & $14 \pm 0.3$ & $23 \pm 1.5^{*}$ & $16 \pm 1.7$ & $18 \pm 2.2$ & $10 \pm 1.4$ & $20 \pm 2.8^{*}$ \\
\hline Plymouth Rock & $15 \pm 0.9$ & $23 \pm 1.5^{*}$ & $21 \pm 2.3^{*}$ & $14 \pm 1.3$ & $11 \pm 0.6$ & $18 \pm 1.1$ \\
\hline Cornish & $15 \pm 0.8$ & $25 \pm 1.7^{*}$ & $20 \pm 3.7$ & $15 \pm 0.5$ & $10 \pm 1.0^{*}$ & $22 \pm 2.2^{*}$ \\
\hline
\end{tabular}

In the initial period of postembryonic development in hybrids, an increase in amylase activity by $49.1 \%$ and $93.1 \%$ was recorded on day 17 and day 14, respectively. Chicks of the parental lines did not show any significant chang- 
es in blood amylase at that time, and its activity remained high until the age of 14 days. This may be due to the intensive growth of the pancreas and the deficit of newly synthesized enzymes, thus, their transcytosis occurred from blood to the acinar cells of the gland to meet the growing body requirement in digestive enzymes. From the 21-day-old age and until the end of the growing period, the blood amylase activity decreased, becoming by the day 35 more than 2 times lower than that of a day old chicks. In the parental lines, the age-related dynamics of amylase activity was different: by the three week age, it declined, and then elevated by the age of 35 days. The proteolytic enzymes showed an undulating decrease in activity: at 35 days old age, the index was $42.9 \%$ lower for the hybrids, $35.7 \%$ lower for the Plymouth Rocks, and $28.6 \%$ lower for the Cornishes, if compared to that of one-day old chicks. This can be explained by the involvement of blood proteases in the regulation of blood pressure. With advancing age, this indicator becomes higher, and the intensity of assimilation in the body vice versa decreases. There was a negative correlation in hybrids found between the activities of proteases in pancreatic tissue and in blood $(r=-0.75)$.

In the first 2 weeks of life, the intensive development of the intestinal microflora occurs [22]. According to our data, the count of cellulosolytic bacteria in meat-type chicks reached high values by the age of 14 days, the chicks of the parent lines and hybrids at this age did not show significant differences. By the age of 21 days, the hybrids had a decrease in the ratio of cellulolytic microorganisms by $26.4 \%$ (from $50.8 \pm 1.84$ to $37.4 \pm 1.25 \%$ ). A similar trend was observed in Cornish chicks (a decrease by $32.0 \%$, from $53.2 \pm 2.47$ to $36.2 \pm 1.57 \%$ ). In the hybrids, the number of cellulolytic bacteria decreased with advancing age, and at the age of 35 days they amounted to $20.3 \pm 0.85 \%$ of the count. In the chicks of the parent lines, an undulating change in the amount of cellulolytic bacteria occurred in course of growing up: at the age of 35 days, $41.0 \pm 1.87 \%$ of these bacteria was recorded in the Plymouth Rocks, and 44.8 $2.27 \%$ in the Cornishes. Therefore, the state of the intestinal microflora depends on many factors, moreover, nutrition and diet do not always play a major part.

The interaction of digestive enzymes with microbiota of the intestine is of particular relevance, since a large number of biological additives are used to stimulate digestion. It is known that the compounds that are not digested in the gastrointestinal tract become food for intestinal microorganisms, and also undergo oxidative deamination and other catabolic processes in liver. It leads to a decrease in the efficiency of food use and the accumulation of intermediate toxic byproducts in the body [23]. The calculation of Pearson linear correlation coefficients between the count of microorganisms and the enzyme activity indices allows us to establish direct relationships between the variables by their absolute values. This work studied such correlations for tissue organ homogenate (Fig.) and blood (data not shown). The resulting coefficients reflected the negative interdependence between the activity of the proteolytic enzymes of the pancreas and the number of cellulolytic bacteria, which indicates a competitive relationship between digestive enzymes and microorganisms. The reason is that the microflora is involved in the final part of the digestive processes (inactivation of intestinal and a number of pancreatic enzymes) and performs a protective function, preventing the development of pathogens in the intestine. The number of lactobacilli required for feed fermentation positively correlated with the activity of all pancreatic enzymes in hybrids, as well as with amylases and proteases in the parental lines. Hybrids had negative correlation between the activity of pancreatic proteases and the presence of Clostridia microorganisms $(r=-0.76)$. This negative correlation may be explained by the fact that the state of commensal 
microflora largely depends on the hydrolysis of the protein in the intestine: the worse the protein is digested, the more favorable the conditions (due to putrefactive processes) for pathogenic microorganisms and the development of inflammatory processes are.

A

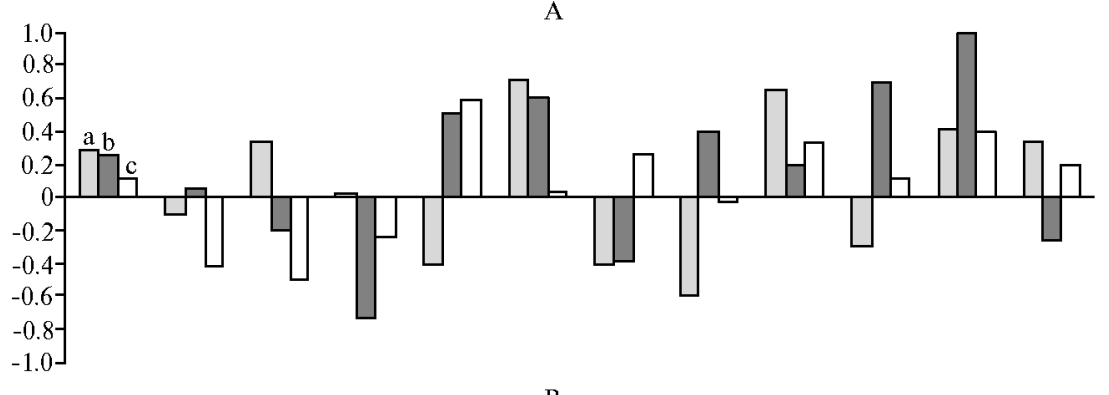

B

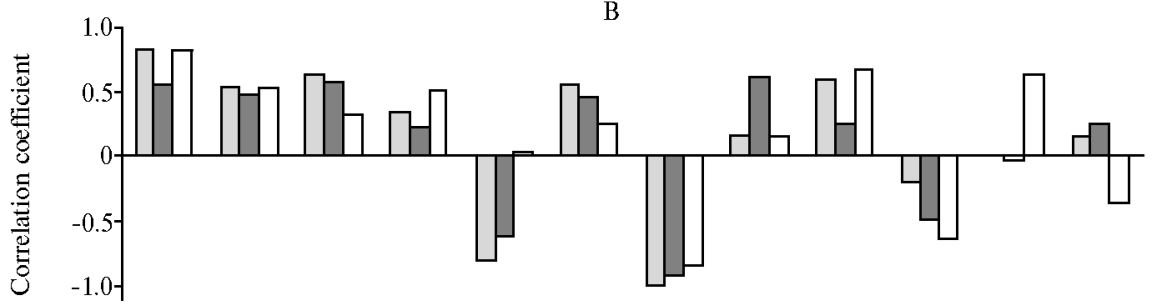

C

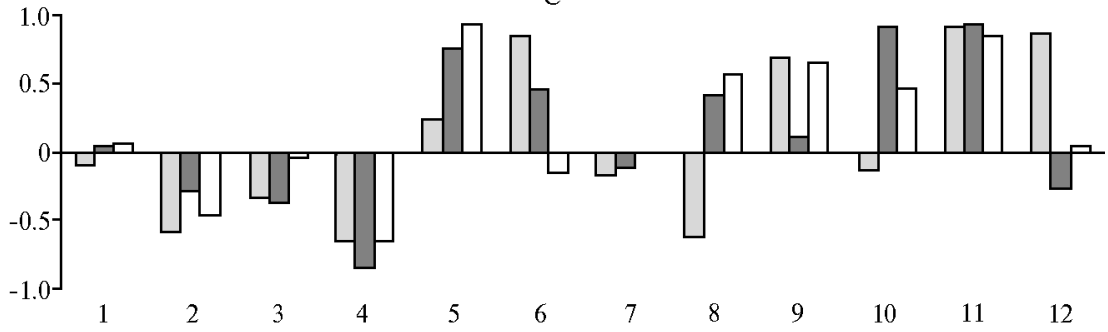

Pearson correlation coefficients between the presence of different groups of bacteria in cecum and the activity of pancreatic amylase (A), lipase (B) and proteases (C) in liver tissue homogenate in hybrid broiler chicks (a) and their parental breed lines Plymouth Rock (b) and Cornish (c) at the age of 35 days: 1 - family Eubacteriaceae, 2 - family Ruminococcaceae, 3 - family Lachnospiraceae, 4 family Clostridiaceae, 5 - phylum Bacteroidetes, 6 - order Lactobacillales, 7 - order Bacillaceae, 8 - order Selenomonadales, 9 - family Enterobacteriaceae, 10 - Staphylococcus sp., 11 - Fusobacterium sp., 12 - Campylobacterium sp. (experimental farm).

Commensal microorganisms also include enterobacteria. However, in this case, there was a positive correlation of their count and activity of all pancreatic enzymes in hybrids and chicks of the Cornish breed. A similar trend was noted for pathogenic bacteria of the genera Staphylococcus, Campylobacter, Fusobacterium, many of which serve as causative agents of infectious diseases in poultry. Consequently, the microbes of these groups participate in digestion in the intestine, and their count is due to the activity of pancreatic enzymes. In studies on fistulled pigs, the results indicated an increase in the amount of $E$. coli after feed intake [24].

So, in meat-type hens during the embryonic period, hybrids have more developed digestion than the parental lines, that is manifested by the presence of amylolytic and lipolytic activities in the embryonic homogenates, and in the intestine and pancreas homogenates. At the age of 1 day, the activity of enzymes in the pancreas is high and does not differ significantly between hybrids and parental lines. The physiological maturation of the pancreas in chicks ends by day 14 of life, and in hybrids it occurs in shorter time. The highest correlation between the activity of proteolytic enzymes of the pancreas and the number of cel- 
lulolytic bacteria was noted for the Clostridia microorganisms. In hybrids and the Plymouth Rocks, the number of lactobacilli positively correlates with the activity of all pancreatic enzymes. The development of commensal and pathogenic microflora in hybrids and chicks of the paternal and maternal lines also positively correlates with the activity of pancreatic enzymes. Therefore, during the embryogenesis, the intensive development of individuals is determined by the activity of digestive enzymes which is higher in hybrids, and during the post-embryogenesis it is due to its correlation to the composition of the intestinal microbiota.

\section{REFERENCES}

1. Torok V.A., Hughes R.J., Mikkelsen L.L., Perez-Maldonado R., Balding K., M a c Alpine R., Pe r c y N.J., O phel-Kelle r K. Identification and characterization of potential performance-related gut microbiotas in broiler chickens across various feeding trials. Appl. Environ. Microbiol., 2011,77(17): 5868-5878 (doi: 10.1128/AEM.00165-11).

2. Sun H., T ang J.W., Y a o X.H., W u Y.F., W a ng X., Feng J. Effects of dietary inclusion of fermented cottonseed meal on growth, cecal microbial population, small intestinal morphology, and digestive enzyme activity of broilers. Trop. Anim. Health. Prod., 2013, 45: 987-993 (doi: 10.1007/s11250-012-0322-y).

3. Stanley D., Denman S.E., Hughes R.J., Geier M.S., Crowley T.M., Chen H., Haring V.R., Moore R.J. Intestinal microbiota associated with differential feed conversion efficiency in chickens. Appl. Microbiol. Biotechnol., 2012, 96: 1361-1369 (doi: 10.1007/s00253-011-3847-5).

4. S c u p h a m A.J. Campylobacter colonization of the Turkey intestine in the context of microbial community development. Appl. Environ. Microbiol., 2009, 75(11): 3564-3571 (doi: 10.1128/AEM.01409-08).

5. Alemka A., Whelan S., Gough R., Clyne M., Gallagher M.E., Carring to n S.D., B ourke B. Purified chicken intestinal mucin attenuates Campylobacter jejuni pathogenicity in vitro. J. Med. Microbiol., 2010, 59: 898-903 (doi: 10.1099/jmm.0.019315-0).

6. Callaway T.R., Edrington T.S., Anderson R.C., Harvey R.B., Genove s e K.J., Ke n ned y C.N., Ve nn D.W., N is b e t D.J. Probiotics, prebiotics and competitive exclusion for prophylaxis against bacterial disease. Anim. Health. Res. Rev., 2008, 9: 217-225 (doi: $10.1017 /$ S1466252308001540).

7. Kerr A.K., Farrar A.M., Wadd e 11 L.A., Wilkins W., Wilhe $1 \mathrm{~m}$ B.J., B u ch e r O., Wills R.W., B a i le y R.H., Varga C., M c Ew e S.A. A systematic review-metaanalysis and meta-regression on the effect of selected competitive exclusion products on Salmonella spp. prevalence and concentration in broiler chickens. Prev. Vet. Med., 2013, 111: 112-125 (doi: 10.1016/j.prevetmed.2013.04.005).

8. Brisbin J.T., Gong J., Orouji S., Esufali J., Mallick A.I, Parvizi P., $\mathrm{S}$ h e w e $\mathrm{n}$ P.E., $\mathrm{S}$ h a rif $\mathrm{S}$. Oral treatment of chickens with lactobacilli influences elicitation of immune responses. Clin. Vaccine Immunol., 2011, 18: 1447-1455 (doi: 10.1128/CVI.05100-11).

9. Sh k u ri n A. Zhivotnovodstvo Rossii, 2016, 12: 18-20 (in Russ.).

10. Lenkova T.N., Egorova T.A., Manukyan V.A., F is in in V.I., Egorov I.A., Lap tev G.Yu., Nik onov I.N., I l' i n a L.A., I y $1 \mathrm{~d}$ y ry m E.A., Fi 1 i pova V.A., Novi k ov a N.I. Ptitsa i ptitseprodukty, 2016, 6: 39-42 (in Russ.).

11. S vihus B., Choct M., C las se n H.L. Function and nutritional roles of the avian caeca: a review. World's Poultry Science Journal, 2013, 69: 249-263 (doi: 10.1017/S004393391300028).

12. Qaisrani S.N., Van Krimpen M.M., Kwakkel R.P., Verstegen M.W.A., Hendriks W.H. Dietary factors affecting hindgut protein fermentation in broilers: a review. World's Poultry Science Journal, 2015, 71: 139-159 (doi: 10.1017/S0043933915000124).

13. Zdunczyk Z., Jankowski J., Kaczmarek S., Juskiewicz J. Determinants and effects of postileal fermentation in broilers and turkeys. Part 1: Gut microbiota composition and its modulation by feed additives. World's Poultry Science Journal, 2015, 71: 37-47 (doi: 10.1017/S0043933915000045).

14. Metodika provedeniya nauchnykh i proizvodstvennykh issledovanii po kormleniyu sel'skokhozyaistvennoi ptitsy. Molekulyarno-geneticheskie metody opredeleniya mikroflory kishechnika /Pod redaktsiei V.I. Fisinina [Poultry feeding: research and practical study. Molecular methods for the analysis of gut microflora. V.I. Fisinin (ed.)]. Sergiev Posad, 2013 (in Russ.).

15. B a t o v Ts.Zh. Sbornik nauchnykh trudov Buryatskogo SKhI (Ulan-Ude), 1971, 25: 122-126 (in Russ.).

16. Mikhailova A.G., Khairullin R.F., Demidyuk I.V., Kostrov S.V., Grinberg N.V., Burova T.V., Grinberg V.Y., Rumsh L.D. Cloning, sequencing, expression, and char- 
acterization of thermostability of oligopeptidase B from Serratia proteamaculans, a novel psychrophilic protease. Protein Expression and Purification, 2014, 93: 63-76.

17. Ky ry liv B.Ya., Gunchak A.V. Vestnik Sumskogo natsional'nogo agrarnogo universiteta, 2016, 5: 170-174 (in Russ.).

18. S t r e l' t s o v V.A., T k a c h e v a N.S. Vestnik Bryanskoi GSKhA, 2012, 5: 25-29 (in Russ.).

19. S o m o v a O.V. Uchenye zapiski UO VGAVM, 2012, 48(1): 142-145 (in Russ.).

20. Egorov I.A., Vertiprakhov V.G., Lenkova T.N., Manukyan V.A., Grozina A.A., Egorova T.A. Ptitsevodstvo, 2017, 2: 23-29 (in Russ.).

21. Vertiprakhov V.G., Grozina A.A., Dolgorukova A.M. The activity of pancreatic enzymes on different stages of metabolism in broiler chicks. Sel'skokhozyaistvennaya biologiya [Agricultural Biology], 2016, 51(4): 509-515 (doi: 10.15389/agrobiology.2016.4.509eng).

22. Buzała M., Janicki B., Czarnecki R. Consequences of different growth rates in broiler breeder and layer hens on embryogenesis, metabolism and metabolic rate: a review. Poultry Sci., 2015, 94(4): 728-733 (doi: 10.3382/ps/pev015).

23. Hermans D., Pasmans F., Messens W., Martel A., Van Immerseel F., R a s s chaert G., Heyndrickx M., V an D e un K., H a e s ebrou ck F. Poultry as a host for the zoonotic pathogen Campylobacter jejuni. Vector Borne Zoonotic Dis., 2012, 12: 89-98 (doi: 10.1089/vbz.2011.0676).

24. Se ys S.A., Sa mpedro F., Hedberg C.W. Assessment of meat and poultry product recalls due to Salmonella contamination: product recovery and illness prevention. J. Food Prot., 2017, 12: 1288-1292 (doi: 10.4315/0362-028X.JFP-16-424). 